\title{
Streptococcus constellatus as an aetiological factor of extensive neck phlegmon complicated by sepsis - case study
}

\author{
Joanna Bilska-Stokłosa $a^{1, A, C-D, F}$, Hanna Tomczak ${ }^{2,3, C-E}$, Katarzyna Hampelska ${ }^{2, B-C}$, \\ Piotr Smuszkiewicz ${ }^{4, B, E}$, Tomasz Zawadzki, ${ }^{1, B-C}$, Krzysztof Osmola ${ }^{1, C, E}$ \\ ${ }^{1}$ Department of Maxillofacial Surgery, Heliodor Święcicki Clinical Hospital, University of Medical Sciences, Poznan, Poland \\ ${ }^{2}$ Central Microbiological Laboratory, Heliodor Święcicki University Hospital, Poznań, Poland \\ ${ }^{3}$ Department of Genetics and Pharmaceutical Microbiology, University of Medical Sciences, Poznań, Poland \\ ${ }^{4}$ Department of Anaesthesiology, Intensive Care and Pain Management, Heliodor Święcicki Clinical Hospital, University of \\ Medical Sciences, Poznan, Poland \\ A - Research concept and design, B - Collection and/or assembly of data, C - Data analysis and interpretation, \\ $D$ - Writing the article, E-Critical revision of the article, F-Final approval of article
}

Bilska-Stokłosa J, Tomczak H, Hampelska K, Smuszkiewicz P, Zawadzki T, Osmola K. Streptococcus constellatus as an aetiological factor of extensive neck phlegmon complicated by sepsis - case study. Ann Agric Environ Med. 2019; 26(2): 252-255. doi: 10.26444/aaem/93735

\begin{abstract}
Introduction. Streptococcus constellatus are opportunistic microorganisms. When immunocompromised patients with concomitant systemic diseases are infected with S.constellatus, the bacteria may cause sepsis.

Case study. A patient was admitted to hospital due to septic shock and multi-organ dysfunction in the course of neck phlegmon. The microbiological system identified S. constellatus in the patient who worked as a dog groomer. These facts confirmed that this aetiological factor may have caused such a serious infection because S. constellatus is a bacterial species found in dogs. It is most likely that the bacteria colonised the patient. Zoonotic transmission of microorganisms is particularly important for the development of infections in dogs and humans. Knowledge about how to treat deep cervical infections is necessary in the daily practice of a maxillofacial surgeon. The right antibiotic can applied only when the strain causing the infection has been identified.
\end{abstract}

\section{Key words}

intensive care unit, zoonoses, infection of deep cervical tissues, Streptococcus constellatus, neck phlegmon

\section{INTRODUCTION}

Streptococcus constellatus is a species of the Streptococcus anginosus group. The microorganisms in this group cause $\alpha$-hemolysis $[1,2]$. These streptococci are part of the physiological microflora of the upper respiratory, urogenital and alimentary tracts. They are opportunistic microorganisms, but they may often cause invasive, purulent infections and can spread through the blood vessels, cause abscesses of the brain, liver, spleen, lungs, bones, endocarditis, and many other infections $[1,3-5]$.

When cachectic, immunocompromised patients with concomitant systemic diseases (diabetes, bile duct diseases, liver diseases, thrombophlebitis) are infected with Streptococcus constellatus, the bacteria may cause bacteraemia or even sepsis. These streptococci usually cause bacteraemia due to the presence of a purulent focus.

At present,the incidence of neck phlegmon is lower due to the wide availability of various drugs, including broad-spectrum antibiotics. However, neck phlegmon is still a danger to life. The most common primary causes are pharyngeal infections, especially tonsillitis, as well as odontogenic infections $[6,7,8]$.

\footnotetext{
Address for correspondence: Joanna Bilska-Stokłosa, Poznan University of Medical Sciences. Department of Maxillofacial Surgery, Heliodor Święcicki Clinical Hospital, Poland, Przybyszewskiego 49, 60-355 Poznań, Poland e-mail: assia_bi@interia.pl

Received: 11.07.2018; accepted: 24.07.2018; first published: 06.09.2018
}

Streptococcus constellatus is a species of non-motile catalase-negative Gram-positive cocci and the species was described in detail in 1991 by Whiley and Brighton. The cells are small $-0.5-1.0 \mu \mathrm{m}$ in diameter, usually form short chains, and the bacteria grow best when they have access to oxygen and there is higher concentration of carbon dioxide in the atmosphere [9].

This article describes a case of abrupt severe streptococcal infection of the deep cervical tissues requiring interdisciplinary treatment.

\section{CASE STUDY}

A 57-year-old patient was admitted to hospital due to septic shock and multi-organ dysfunction in the course of neck phlegmon. The patient had been admitted to another hospital due to inflammatory infiltration of the oral cavity floor and decompensated diabetes. The patient admitted to the Department of Anaesthesiology and Intensive Therapy was in a serious condition. He was awarded 14 points according to the SOFA scoring system - predicted mortality $>95 \%$. He was intubated and mechanically ventilated due to respiratory insufficiency. He was haemodynamically unstable and required infusion of catecholamines. Acute renal failure was diagnosed. Laboratory tests produced the following results: CRP $681.1 \mathrm{mg} / \mathrm{l}$, procalcitonin $74.18 \mathrm{ng} / \mathrm{ml}$, leucocytosis $12.30 \times 10^{3} / \mu 1$. Extensive bilateral inflammation of deep cervical tissues and the presence of gas spaces were diagnosed 
in computed tomography. Immediate incision of the neck phlegmon was performed and drained [Fig. 1]. Material was collected for microbial tests. The patient's decayed tooth roots 38 and 48 were extracted. There was no inflammation diagnosed in the patient's oral cavity. The material collected during the surgery was sent to the Microbiological Laboratory, where it was cultured on standard microbiological media: Columbia agar with $5 \%$ sheep blood, mannitol salt agar, MacConkey agar, enterococci culture medium and broth medium (Oxoid). Cultures for anaerobic flora were also prepared on Scheadler agar and broth medium. Microorganisms were cultured for 5 days under anaerobic conditions. After 24 -hours incubation at $35^{\circ} \mathrm{C}$, a-haemolytic streptococci were the only microorganisms cultured. Further diagnostics was carried out with a Vitek MS mass spectrometry system (bioMerieux). The system identified cultured microorganisms as Streptococcus constellatus. These bacteria are part of the physiological flora of the oral cavity, where they are one of many microbial species of the abundant biome. However, they formed a monoculture in the current test, and were therefore identified as the aetiological factor of the infection.

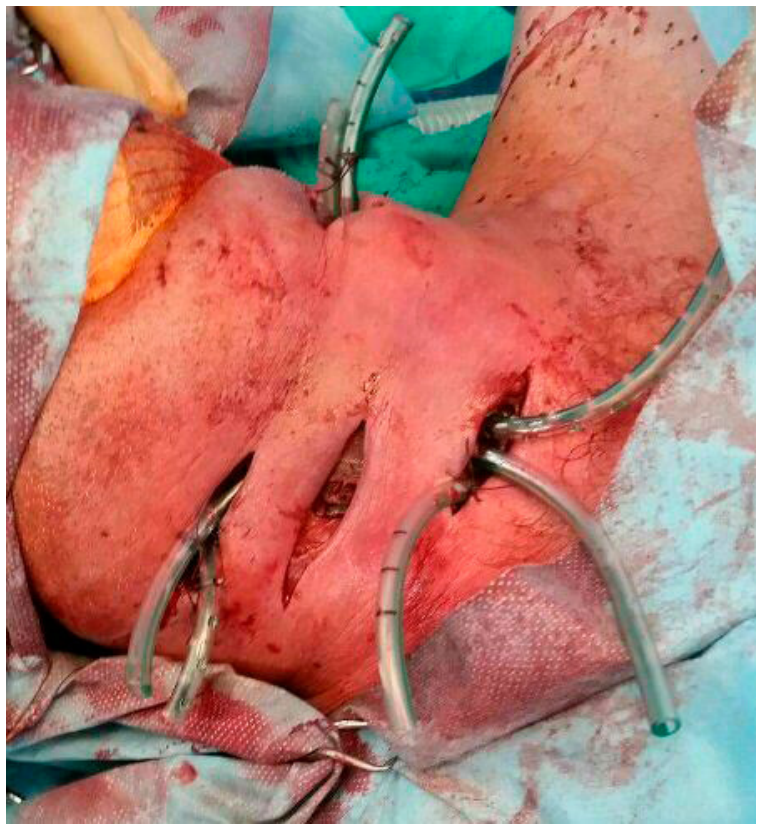

Figure 1. Incision and drained neck phlegmon bilateral

Due to the patient's severe state and renal failure, continuous renal replacement therapy with (CVVHD Ci-Ca) citrate anticoagulation was implemented. Additionally, the patient underwent numerous bronchofiberoscopies and had a pleural drainage catheter installed due to pleural empyema. A cardiologist was consulted due to the patient's advanced cardiovascular disease (extensive left ventricle contractility disorders with severe systolic dysfunction in the echo test, EF 15-20\%). Insulin therapy was also implemented and the glycaemic level was normalised.

On day 38 of the therapy there was a sudden cardiac arrest in the PEA mechanism. Initially the patient received antibiotics empirically (linezolid and metronidazole). When microscopy showed that Gram-positive cocci were responsible for the infection, antibiotic therapy was continued. Having received the results of another microbial test, the antibiotic therapy was modified and the patient received meropenem and metronidazole. Further samples were regularly collected for follow-up examinations, but Streptococcus constellatus was no longer cultured. The following strains of microorganisms were cultured during the first days of the patient's stay at the Intensive Therapy Unit: Acinetobacter baumannii, Staphylococcus aureus, Proteus mirabilis, Candida krusei, Candida albicans, and Stenotrophomonas maltophilia. Later Pseudomonas aeruginosa and Enterococcus faecalis were also cultured.

Due to numerous complications caused by decompensated diabetes (e.g. diabetic foot) [Fig. 2] and pneumonia), which additionally complicated the therapy, it was necessary to change the antibiotic therapy scheme several times according to the patient's clinical condition and the results of microbial

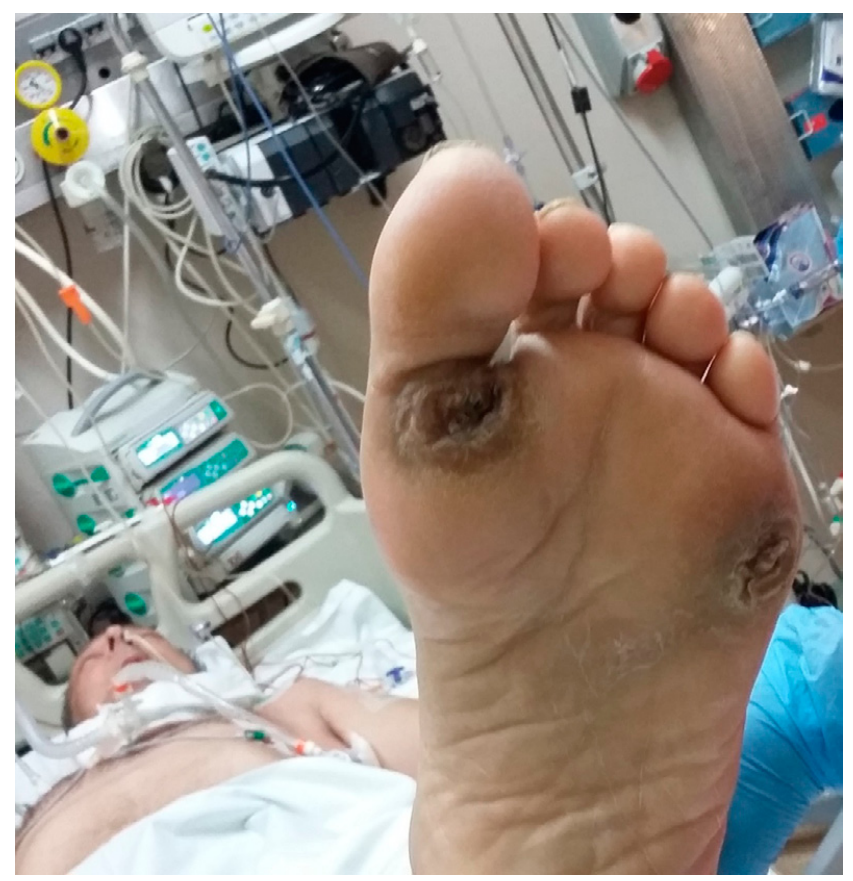

Figure 2. Diabetic foot

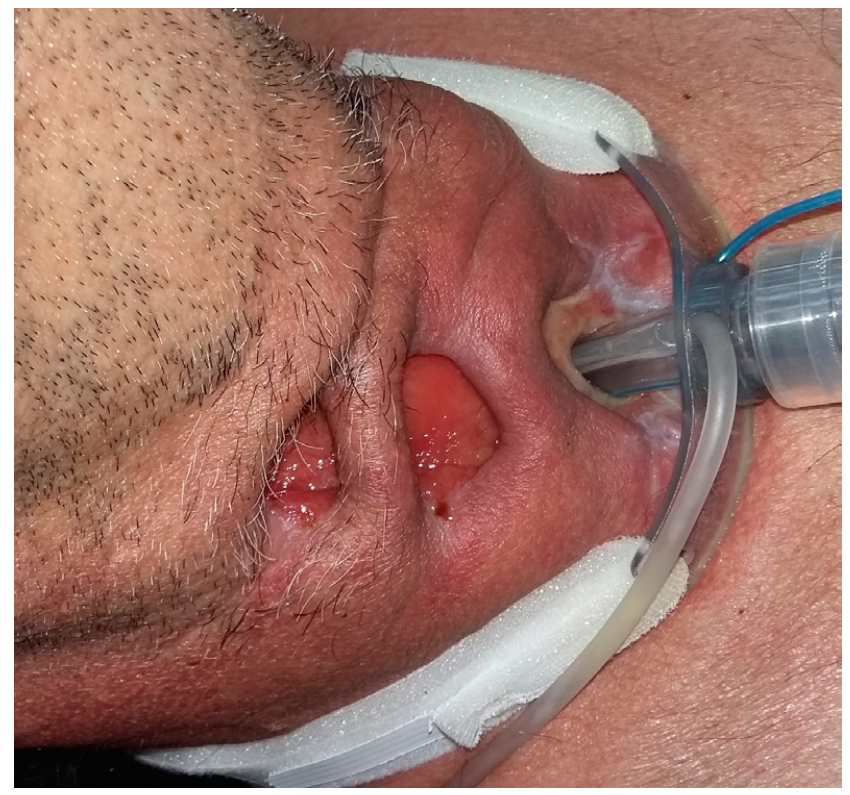

Figure 3. Wound healing by granulation 
tests. The surgical wound needed to be revised a few times and it was necessary to remove deeply located necrotic tissues. When the drains were removed from the patient's neck, the wounds were left to heal by granulation. Calcium alginate dressings with silver were applied for the antibacterial effect [Figs. 3 and 4]. After two months the patient's state improved considerably and he was discharged from the Intensive Therapy Unit.

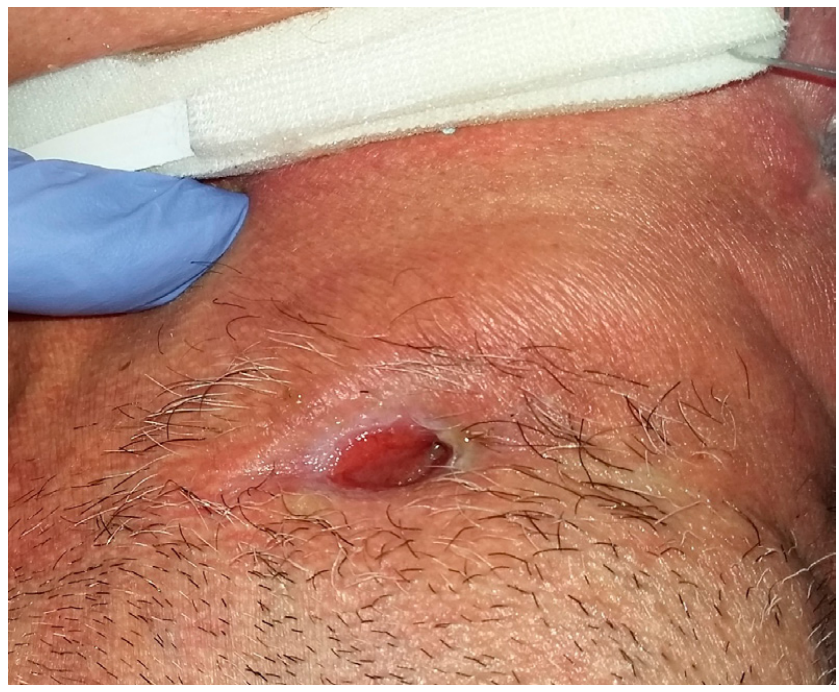

Figure 4. Wound healing by granulation

\section{DISCUSSION}

In this case study, Streptococcus constellatus formed a monoculture. This fact indicated serious infection correlated with the patient's severe state. This course of the infection might indicate immunodeficiency. The patient had been suffering from diabetes for many years. When the patient was hospitalised, he suffered from complications in his body organs caused by inadequate treatment of diabetes. The patient did not observe a strict diet, which is particularly significant in cases of infections. The patient's abundant colonisation with Streptococcus constellatus may also have been caused by his everyday contact with animals, a fact also observed by Bancescu G. et al. [10]. The patient worked as a dog groomer and worked in partnership with a veterinary physician. These facts confirmed that this aetiological factor may have caused such a serious infection as Streptococcus constellatus is a bacterial species found in dogs. It is most likely that the bacteria colonised the patient. Next, the infection developed due to favourable conditions (immunodeficiency). Infections are preceded by the state of being a pathogen carrier.

Streptococcus constellatus is often isolated as an aetiological factor of cocci-induced infections in pups and young dogs due to their underdeveloped or malfunctioning immune system. Purulent dermatitis is the most common clinical symptom observed in animals. When humans contact dogs colonised by Streptococcus constellatus, the microorganisms may also colonise the humans and, under favourable conditions, cause serious infections. Zoonotic transmission of microorganisms is particularly important for the development of infections in dogs and humans [10].

All the microorganisms cultured from the patient were characterised by multidrug resistance (MDR). These pathogens are always related with staying at an ICU, immunodeficiency, and above all, with long-term broadspectrum antibiotic therapy. Infections may be caused not only by resistant bacteria but also by fungi. First, the patient becomes colonised by multidrug resistant microorganisms which cause infections, and in most cases, infections develop in consequence of colonisation. The emergence of new microbial species causes the need to apply new antibiotics because there is no drug that is effective against all microorganisms. The places colonised by physiological bacterial flora become replaced with alert pathogens because only these organisms can endure the long-term presence of antibiotics in the environment. Some microorganisms are eradicated, while others are generated; it is therefore necessary to apply more antibiotics and/or antifungal drugs. It is also necessary to stress the fact that material should be collected for analysis at the beginning of an infection. This is usually the only moment when material can be collected and the actual aetiological factor of the infection can be identified. In this case study, if the material had not been collected from the patient on admission to the ICU, the cause of the severe infection could not have been identified.

Streptococcus anginosus group (SAG) is a specific group among viridans streptococci due to its high pathogenicity and predisposition for the formation of abscesses. The group is a predominant aetiological factor in life-endangering infections developing in the head and neck. According to recent studies, Streptococcus constellatus, after Streptococcus intermedius, is the second most common cause of these infections, [11].

Knowledge about how to treat deep cervical infections is necessary in the daily practice of a maxillofacial surgeon [12]. A rapidly progressing purulent process may spread in the interfascial spaces of the neck which may affect the mediastinum, and be the starting point of a septic shock $[6,13,14]$. The treatment plan must be based on the entire clinical picture, the results of laboratory investigations and imaging tests.

Due to the severe clinical course of the infection and healing problems the patient had to undergo multiple surgeries. Microbial tests are important both in the application of proper treatment and identifying the actual aetiological factor of the infection [15]. The right antibiotic can applied only when the strain causing the infection has been identified. Synchronised cooperation of an interdisciplinary team increases the positive effect of the treatment of severe, complicated infections.

\section{REFERENCES}

1. Ruoff KL. Streptococcus anginosus ("Streptococcus milleri”): the unrecognized pathogen. Clin Microbiol Rev. 1988; 1: 102-108.

2. Wein Ping Ng K, Mukhopadhyay A. Streptococcus constellatus bacteremia causing septic shock following tooth extraction: a case report. Cases J. 2009; 2: 6493.

3. Whiley RA, Beighton D, Winstanley TG, Fraser HY, Hardie JM. Streptococcus intermedius, Streptococcus constellatus, and Streptococcus anginosus (the Streptococcus milleri group): association with different body sites and clinical infections. J Clin Microbiol. 1992; 30: 243-244.

4. Bantar C, Fernandez Caniga L, Relloso S, Lanza A, Bianchini H, Smayevsky J. Species belonging to the "Streptococcus milleri" group: anti-microbial susceptibility and comparative prevalence in significant clinical specimens. J Clin Microbiol. 1996; 34: 2020-2022. 
5. Clarridge JE, III, AttorriS, Musher DM, HebertJ, DunbarS. Streptococcus intermedius, Streptococcus constellatus, and Streptococcus anginosus ("Streptococcus milleri group") are of different clinical importance and are not equally associated with abscess. Clin Infect Dis. 2001; 32: 1511-1515. doi: 10.1086/320163.

6. Kawczyński M, Amernik K, Kelar I, Jaworowska E, Paradowska-Opałka B. Zakażenia ropne głębokich przestrzeni szyi w Klinice Otolaryngologii PUM w okresie ostatnich 5 lat. Pol. Przegląd Otorynolaryngol 2012; 4 (1): 314-318.

7. Lee YQ, Kanagalingam J. Bacteriology of deep neck abscesses: a retrospective review of 96 consecutive cases. Singapore Med J. 2011; 52: 351-5.

8. Bottin R, Marioni G, Rinaldi R, Boninsegna M, Salvadori L, Staffieri A. Deep neck infection: a present-day complication. A retrospective review of 83 cases (1998-2001). Eur Arch Otorhinolaryngol. 2003; 260: 576-9.

9. Whiley RA, Hall LMC, Hardie JM, Beighton D. A study of small-colony, beta-haemolytic, Lancefield group $\mathrm{C}$ streptococci within the anginosus group: description of Streptococcus constellatus subsp. pharyngis subsp. nov., associated with the human throat and pharyngitis. Int J Syst Bacteriol. 1999; Oct; 49 Pt 4: 1443-9.
10. Bancescu G, Carmen D, Bancescu A, Hirjau M. The Susceptibility To Antibiotics Of Some Streptococcus Constellatus Strains Isolated From Odontogenic Infections Farmacia 2016; 64(1): 58-60.

11. Faden H, Mohmand M. Infections Associated With Streptococcus Constellatus in Children The Pediatric Infectious Disease J. 2017; 36(11): 1099-1100.

12. Osborn TM, Assael LA, Bell RB. Deep space neck infection: principles of surgical management. Oral Maxillofac Surg Clin North Am. 2008; 20(3): 353-65.

13. Karkos PD, Leong SC, Beer H, Apostolidou MT, Panarese A. Challenging airways in deep neck space infections. Am J Otolaryngol. 2007; 28: 415-8.

14. Markowski J, Dziubdziela W, Wardas P, Piotrowska A, SowińskaKrzyżanowska I, Gierek T, et al. Ropowice głowy i szyi - diagnostyka i leczenie - obserwacje własne. Otolaryngol Pol. 2012; 66: 207-13.

15. Cheng Z, Yu J, Xiao L, Lian Z, Wei Y, Wang J. Deep neck infection: clinical analyses of 95 cases. Zhonghua Er Bi Yan Hou Tou Jing Wai Ke Za Zhi. 2015 Sep; 50(9): 769-72. 